\title{
O ENSINO DA CONCEPÇÃO ESTRUTURAL NO ATELIÊ DE PROJETO DE EDIFÍCIOS VERTICAIS: UM ESTUDO DE CASO NA UNIVERSIDADE FEDERAL DO RIO GRANDE DO NORTE

\author{
TEACHING STRUCTURAL DESIGN IN TALL BUILDINGS STUDIO: A CASE STUDY AT \\ FEDERAL UNIVERSITY OF RIO GRANDE DO NORTE
}

\author{
Camila Cavalcanti Resende, Maísa Fernandes Dutra Veloso ${ }^{2}$
}

\section{RESUMO:}

A dificuldade de inserção da estrutura nas etapas iniciais do projeto arquitetônico tem sido discutida na literatura e uma das causas apontadas remete à questão do ensino, notadamente, a falta de integração entre o ensino de estruturas e o ensino do projeto em ateliê. No Brasil, na formação profissional generalista em Arquitetura e Urbanismo, essa falta de integração torna-se um desafio ainda maior face à variedade de informações e conhecimentos necessários ao desenvolvimento de projetos de edifícios verticais. 0 objetivo principal deste artigo é discutir a inserção da concepção estrutural na disciplina de Projeto de Arquitetura 4 (PA4) do Curso de Arquitetura e Urbanismo (CAU) da Universidade Federal do Rio Grande do Norte (UFRN), cujo enfoque é a verticalidade. Metodologicamente, foram realizadas: análise documental da estrutura curricular do CAU e do plano de curso de PA4, observação sistematizada das atividades em ateliê, entrevistas com os alunos e o professor e, por fim, análise de dez projetos desenvolvidos pelas equipes. Com base nos dados coletados, foi possível verificar quais métodos e técnicas de ensino proporcionaram uma maior integração das estruturas no processo de projeto, ressaltando-se o desenvolvimento de um modelo físico no início do processo, a esquematização dos elementos estruturais nos estudos preliminares e o incentivo à concepção estrutural durante a elaboração do pavimento tipo. Constatou-se, também, que a integração da concepção estrutural no ateliê de projeto adiciona mais uma dificuldade ao processo de ensino/aprendizado, mas é uma prática muito mais reflexiva do que as formas usuais do ensino de estruturas.

PALAVRAS-CHAVE: Educação; Arquitetura; Estrutura; Integração.

\section{ABSTRACT:}

Structure insertion in the architectural design firsts steps is an issue that has been discussed in the literature for a while and one of its causes refers mainly the gap between the structural and architectural teaching in the studio. In Brazil, with the generalist professional qualification in Architecture and Urbanism this lack of integration become a bigger challenge by reason of the diversity of information and knowledge required in designing tall building projects. The goal of this article is to discuss the insertion of the conceptual structural design inside the studio module of the Architecture Project 4 (PA4) at Federal University of Rio Grande do Norte (UFRN) in the under-graduation course of Architecture and Urbanism (CAU), which focus is vertical buildings. Methodologically, were accomplished: the document analysis of the CAU's curricular structure and the PA4 course plan, a systematized observation of the activities in the classes, interviews with students and professor, and lastly, the analysis of ten projects developed by the students. Based on the data collected, it was possible to identify which methods and techniques promoted a better integration of the structures in the design process, underscoring the development of physical models at the design process beginning, the structural element's organization in preliminary designs and the encouragement for the structural design during the floor plans elaboration. In addition, the structural design integration in the studio adds another difficulty to the teaching / learning process, but it is a much more reflective practice than the usual forms of teaching Structures.

KEYWORDS: Education; Architecture; Structure; Integration.

How to cite this article:

RESENDE, C.; VELOSO, M.. O ensino da concepção estrutural no ateliê de projeto de edifícios verticais: um estudo de caso na Universidade Federal do Rio Grande do Norte. Gestão \& Tecnologia de Projetos. São Carlos, v16, n2, 2021. https://doi.org/10.11606/gtp.v16i2.162464
Fonte de Financiamento: Coordenação de Aperfeiçoamento de Pessoal de Nível Superior (CAPES).

Conflito de Interesse: Declara não haver.

Ética em Pesquisa: Projeto Aprovado pelo CEP HUOL/UFRN na Plataforma Brasil - CAAE 00360818.3.0000.5292.

Submetido em: 20/09/2019. Aceito em: 02/02/2020
${ }^{1}$ Universidade Federal Programa de Pósgraduação em Urbanismo.

2 Universidade Federal Programa de PósArquitet Arquitetura 


\section{INTRODUÇÃO}

A problemática da integração de conteúdos no ateliê de projeto nos cursos de Arquitetura e Urbanismo (AU) vem sendo discutida já há algum tempo. Se considerarmos como referência inicial as discussões apresentadas no livro "Projeto Arquitetônico: disciplina em crise, disciplina em renovação" (COMAS et al., 1985), já se passam mais de trinta anos. Dentre os temas recorrentes para superação do problema, destacam-se a necessidade de aperfeiçoamento da didática do projeto e a consideração dos novos paradigmas advindos das inovações computacionais. Nesse contexto, o ensino da concepção estrutural, que é vinculado diretamente à arquitetônica, se enquadra em muitas dessas discussões. No nosso estudo, o foco repousa sobre a didática necessária a essa integração.

A concepção arquitetônica é a essência do ensino de Arquitetura através da prática do projeto (BOUDON et al., 2000). Essa didática se inicia partir da fase de estudos preliminares e representações diversas e vai até a o "modelo de realização", que é o produto final - o projeto, que deve considerar também os conteúdos das outras disciplinas do curso. Para tanto, a concepção tem uma organização característica e um local determinado, que é o ateliê de projeto, com carga horária em geral mais expressiva, quando comparada aos outros componentes do curso (LEBAHAR, 2001). Em se tratando da integração de conteúdos no ateliê de projeto, Hélio Piñón (1998) afirma que na concepção formal, que é uma atividade contínua, todas as matérias que caracterizam o ensino de Arquitetura, tornam-se critérios válidos. Sendo assim, apenas a transmissão deles não é suficiente, tornando-se necessária a conscientização acerca do projeto de arquitetura e sua relação com as disciplinas afins (PIÑóN, 1998, p. 148). Em virtude disso, o ensino do projeto arquitetônico não se enquadra nos "paradigmas educacionais" convencionais porque assume uma formação generalista e universalista, uma vez que é composto de princípios disciplinares de vários campos do conhecimento, desde as artes e humanidades até as ciências exatas e tecnologias. 0 papel do docente é sobretudo ensinar os alunos a "sentir, pensar e fazer", para então projetar, levando em consideração aspectos culturais e atemporais, com uma consciência crítica, estética e ética. É importante também ensinar a "ver", ou seja, refinar o olhar para experiências arquitetônicas pessoais e bibliográficas do cotidiano (PINTO, 2007).

De modo geral, observa-se nas Escolas de Arquitetura do Brasil um déficit na formação dos arquitetos e urbanistas no campo das estruturas, em face à divisão histórica entre arte e técnica, a partir de dois modelos de formação: a Escola de Belas Artes e a Escola Politécnica. Após 1964, iniciativas didático-metodológicas para o ensino de estruturas surgiram com o intuito de promover o desenvolvimento do "sentimento estrutural" ${ }^{i}$ nos alunos, nas quais verificou-se a importância do conhecimento do comportamento das estruturas e a necessidade de desenvolvimento de um raciocínio sobre elas por parte dos alunos (SARAMAGO, 2011). No cenário atual, ainda se observa a persistência de uma formação dividida entre o artístico e o técnico na formação do profissional de Arquitetura, visto que ainda permanecem conflitos didáticos que causam evidentes consequências no aprendizado da concepção estrutural. As disciplinas de estruturas, na maior parte das vezes, são ministradas por profissionais de formação excessivamente técnica e afastada do ato de projetar, o que ocasiona para os estudantes uma desconexão entre as duas vertentes do conhecimento construtivo (REBELLO; LEITE, 2015). Nesse sentido, qual o caminho para o ensino da concepção estrutural dentro do ateliê, levando em consideração sua indissociável relação com a arquitetura? De maneira suscinta, a compreensão dos padrões de funcionamento das estruturas, isto é, deformações, influência da forma e das dimensões das peças resistentes aos esforços, é o ponto essencial na concepção da estrutura (LOBOSCO; CÂMARA, 2018). 
Seguindo a ideia do ensino integrado de estruturas ao de projeto arquitetônico, Maria Vrontissi (VRONTISSI et al., 2018) afirma que existe a prática da linearidade no processo de projeto quando se trata da concepção estrutural, no qual ela só acontece tardiamente e para se adequar a uma ideia arquitetônica já definida. No caso de edifícios de múltiplos pavimentos, quanto mais altos, maiores as cargas gravitacionais e laterais que serão suportadas, estabilizadas e transmitidas ao solo, aumentando, consequentemente, as questões estruturais a serem resolvidas. Dependendo da proporção e da altura do edifício, a estrutura torna-se dominante no processo de projeto e irá definir não só a forma, mas também a disposição dos elementos estruturais e, em alguns casos, a organização dos espaços (WHITEHEAD, 2020).

Tendo em vista as particularidades da didática da disciplina de Projeto de Arquitetura e a ampla quantidade de conteúdos integralizados no seu contexto, procurou-se entender como se dá o ensino da concepção estrutural e quais seriam os meios de melhor integrá-lo dentro do ateliê. Este artigo apresenta um estudo piloto, realizado no semestre de 2018.2, na disciplina de Projeto de Arquitetura 4, cujo tema é Verticalidade (produção de edifício altos, de múltiplos pavimentos), para verificação da metodologia proposta para uma tese em andamento no Programa de Pós-Graduação da UFRN (PPGAU/UFRN). O objetivo principal é entender e avaliar como ocorre a integração da concepção estrutural no ensino de Projeto de Arquitetura. Para tanto, pretende-se verificar como se dá, de modo geral, a integração da concepção estrutural no âmbito dos ateliês de projeto dos cursos de AU, e propor recomendações para melhorias do ensino nesse ambiente de aprendizagem. A pesquisa, qualitativa e de caráter exploratório, foi aprovada pelo Comitê de Ética da instituição com cinco etapas: 1- Análise da Ementa e do Plano de Curso, 2- Observação direta da disciplina, 3- Entrevista Coletiva com os alunos, 4- Entrevista com o professor e 5- Análise dos Projetos desenvolvidos pelos discentes. Para cada uma dessas etapas, foram elaborados roteiros e fichas de observação próprios, contemplando as seguintes categorias analíticas: momento e interação da concepção arquitetônica e da estrutural, influência da estrutura no projeto, importância das disciplinas anteriores no desenvolvimento do trabalho, produção de modelos físicos, atuação do docente de projeto e contribuição do professor de estruturas. As análises foram desenvolvidas com base na literatura inerente às temáticas trabalhadas - ensino de projeto, ensino de estruturas e projetos de edifícios verticais.

\section{DISCUSSÃO: A PROBLEMÁTICA DO ENSINO DE ESTRUTURAS}

Sobre as disciplinas de Estruturas e sua didática, há atualmente uma discussão sobre a ênfase da formação: o instrucionismo ${ }^{\text {ii }}$ em oposição a uma abordagem construcionistaiii, metodologias apresentadas nas teses de Ballarotti (2015) e Di Pietro (2000). Há, ainda, um debate sobre sua reformulação pedagógica, principalmente visando a interdisciplinaridade e a inserção de conteúdos transversais no curso (NÓBREGA; COSTA, 2017).

Segundo alguns autores (WHITEHEAD, 2015; CHIUINI, 2006; LARSEN, 2003), o ensino de estruturas nas Faculdades de Arquitetura é uma adaptação do modelo utilizado nas Escolas de Engenharia. Ao invés de transmitirem simplesmente os conteúdos sobre o Projeto Estrutural, eles podem ser integrados de forma crítica ao Projeto Arquitetônico. Isto é, os alunos precisam compreender a função dos sistemas estruturais nos seus projetos e procurar um meio de integrar o conhecimento adquirido nos módulos de tecnologia, para que consigam desenvolver habilidades intuitivas e reflexivas relacionadas à concepção estrutural. Contrariamente, tais disciplinas permanecem restritas a uma faixa de tópicos curriculares e métodos analíticos das estruturas (WHITEHEAD, 2015). Segundo Rebello e Leite (2015), a departamentalização é a causa do distanciamento entre as duas partes e a formação exageradamente técnica provoca nos estudantes de arquitetura a sensação de que o que está sendo ensinado é desprovido de sentido. Os autores ainda colocam outra deficiência que se pode apontar é a forma de inserção 
das disciplinas de estrutura na grade curricular. Na maioria das escolas, a primeira a tratar do assunto - em geral, a Resistência dos Materiais - é colocada a partir do terceiro semestre do curso, quando os alunos já tiveram no mínimo um ano de informações sobre projeto de arquitetura e sem qualquer referência a respeito da sustentação estrutural" (REBELLO; LEITE, 2015). Existem técnicas que podem ser utilizadas além das aulas tradicionais de estruturas: produção de modelos físicos, testes de cargas, simulação e análise estrutural por meio de programas interativos de computador, e, por último, a integração do ensino de estruturas no ateliê de projeto (HERR, 2013, grifo nosso).

Dentro do ensino de estruturas é importante compreender que a concepção estrutural, como explica Olga Larsen (2003), é a maneira não matemática de conceber uma forma estrutural: 1a partir dos elementos da natureza, 2- usando a intuição; 3- a partir de precedentes; 4- pelos princípios científicos e dos materiais; 5 - através de modelos físicos; 6- por meio de novas ferramentas computacionais. Para a autora, a concepção estrutural compete mais em encontrar a forma adequada de sustentação do que tentar achar as dimensões de seus elementos. Compreende que a lógica estrutural está relacionada à eficiência que um edifício tem em se manter em pé (considera que os elementos tensionados são os mais eficientes, os em compressão menos e os em momento fletor bem menos), sendo assim, a escolha do material utilizado é o primeiro passo a ser observado e a intuição no desenvolvimento de projeto deve vir antes dos conceitos da análise matemática da estrutura (LARSEN, 2003; SIMONEN, 2014). 0 conhecimento do dimensionamento estruturas não assegura esse sentimento sobre o comportamento estrutural (PRESMUM apud MACNAMARA, 2012). Entende-se que a didática desse tipo de concepção pode estar inserida no ensino de estruturas ou estar vinculada à prática de projeto no ateliê.

Sendo assim, vale ressaltar duas iniciativas da inserção da concepção estrutural nas Faculdades de Arquitetura: 1- experiência de integração com a estrutura no primeiro ano do estúdio; 2aplicação dos conceitos de "Problem and Project Based Learning" (PPBL) no ensino de sistemas estruturais (EMAMI; BUELOW, 2016; WETZEL, 2012). Sobre esse aspecto, o caráter interdisciplinar do ensino de projeto permite a aplicação desse método que tem como objetivo um aprendizado ativo promovendo um diálogo entre arte e racionalidade e proporcionando uma aproximação entre o espaço almejado e sua estrutura (ILKOVIČ; ILKOVIČOVÁ; ŠPACEK, 2014).

Larsen (2003) aponta que a produção de modelos físicos é uma ferramenta poderosa para o form-finding de uma estrutura, uma vez que ela tem o poder de mostrar como a forma irá se comportar com a gravidade. Apesar da modelagem e a análise numérica dos sistemas estruturais terem evoluído significativamente, ainda há projetistas que usam essa técnica para tratar de formas mais complexas (LARSEN, 2003). Em um estudo na Universidade Estadual de Campinas, verificou-se que estudantes também perceberam a fluidez das ideias tridimensionais e entenderam os espaços mais rapidamente quando utilizam o isopor na concepção (FLORIO; TAGLIARI, 2017). Modelos físicos permitem o entendimento da performance estrutural e a interpretação qualitativa; enquanto componentes do processo de projeto, são com frequência associados a certas tipologias e a elementos estruturais já conhecidos (treliças, pórticos, etc.) e, na maioria das vezes, o espaço é definido por um padrão estrutural, por exemplo, o material e a tecnologia, ou mesmo por soluções ótimas em termos de engenharia. Portanto, diferente do modelo estrutural, aquele derivado do paradigma científico de laboratório (mais utilizado nas Escolas de Engenharia), e do modelo físico mais abstrato (mais comum nas Escolas de Arquitetura), existe um híbrido proveniente da fusão das duas disciplinas, o qual tem sido relatado em muitas conferências da área (VRONTISSI et al., 2018). 
Como visto anteriormente, os conteúdos de estruturas são parte importante para o entendimento da materialização dos espaços e existem procedimentos didático-metodológicos qualitativos para a inserção mais adequada das estruturas na formação em AU. Portanto, é pertinente a investigação sobre como está sendo ministrado o ensino da concepção estrutural dentro do ateliê de Arquitetura e, especialmente, como ela é assimilada e qual o rebatimento nos projetos dos alunos. É o que veremos a seguir.

\section{PESQUISA APLICADA: O ENSINO DE ESTRUTURAS NO ATELIÊ DE PROJETO}

Como anunciado anteriormente, as etapas e procedimentos que compuseram a análise do componente curricular Projeto de Arquitetura IV do CAU-UFRN foram: análise do Plano de Curso da disciplina, observação sistematizada direta em sala de aula, entrevista coletiva com os alunos e individual com o professor responsável e a análise dos projetos produzidos pelos discentes. Para cada etapa, foi elaborado um roteiro específico, porém considerando as categorias analíticas que permeiam toda a investigação. A referida disciplina foi escolhida para estudo piloto com base nos seguintes critérios: 1- o tema (Verticalidade); 2- a proposta de integração com o componente curricular de estruturas do mesmo período letivo e 3- a facilidade de acesso para realização do estudo.

\section{O CURSO DE ARQUITETURA E URBANISMO DA UFRN}

O Curso de Arquitetura e Urbanismo da Universidade Federal do Rio Grande do Norte (CAUUFRN) faz parte do Departamento de Arquitetura e Urbanismo (DARQ) e está localizado no Centro de Tecnologia (CT), no campus central da UFRN. 0 corpo docente é composto por 38 professores, sendo 32 permanentes e 6 substitutos. Ingressam no total 40 alunos por ano, sendo 20 a cada semestre letivo. 0 curso é ofertado desde 1973, com base no currículo A-1, o qual passou por quatro reformas curriculares, o que denota uma preocupação pedagógica constante. Em 1976 se deram as primeiras iniciativas de reforma curricular, que tiveram como objetivo o agrupamento dos períodos em módulos e repensavam a organização do currículo de acordo com o enfoque de cada módulo. Atualmente, vigora o currículo A-5 que organiza as disciplinas e os conteúdos em cinco grandes áreas de estudo, estabelecendo, também, temas para cada período (estabelecido desde o A-3). Atualmente, o curso se prepara para uma nova reformulação curricular (o A-6) que prevê a implementação do Ateliê Integrado de Projeto com base em experiências didáticas que vem sendo realizadas desde 2015 no quinto e sétimo períodos do curso.

\section{ESTUDO DE CASO: DISCIPLINA DE PROJETO DE ARQUITETURA 4 (PA4)}

A disciplina de Projeto de Arquitetura IV (PA4) está inserida no sexto período - Verticalização e Paisagem - do Currículo A5 do CAU-UFRN e tem uma carga horária de 90 horas-aula. 0 Projeto da disciplina é um edifício vertical ${ }^{\text {iv }}$ de uso misto no bairro de Barro Vermelho na cidade de Natal no Rio Grande do Norte (RN) em nível anteprojeto. Os alunos desconheciam o tema da pesquisa de doutorado durante o acompanhamento que foi feito na disciplina ao longo do semestre 2018.2, apenas tendo sido informados a esse respeito ao final do semestre letivo, no momento da entrevista coletiva. Na ocasião, o professor e todos os alunos concordaram em participar da pesquisa e assinaram o Termo de Consentimento Livre e Esclarecido (TCLE), com autorização de registro de voz e imagem e o Termo de Concessão do Projeto Final da disciplina para fins de análise. Os resultados desse estudo são apresentados nos itens seguintes. 


\section{ANÁLISE DO PLANO DE CURSO}

O Plano de Curso (PC) apresenta os dados da disciplina, o contato do professor, a ementa, os objetivos, os procedimentos metodológicos, a forma de avaliação, as referências bibliográficas e o conteúdo programático de maneira clara e objetiva.

Tanto na ementa quanto no objetivo geral, no PC fica claro o comprometimento em estudar as especificidades e aplicação das estruturas nos edifícios verticais. Na primeira, esclarece que se pretende complementar o conhecimento adquirido nas disciplinas de Projeto de Arquitetura dos semestres anteriores do CAU, acrescentando a formação em projeto de edifícios verticais. Aponta como pontos importantes a estrutura, a circulação e as instalações prediais, e é compreensível que os três assuntos estejam evidenciados porque são consoantes com o tema. Já o objetivo geral é "projetar um edifício vertical em nível de anteprojeto, levando em consideração as particularidades da inserção desse tipo de objeto arquitetônico (...), dentre elas, a estrutura" (Plano de Curso de Projeto de Arquitetura 4, 2018.2).

Sobre os procedimentos metodológicos, as atividades estavam de acordo com a proposta de desenvolvimento do projeto: realização e apresentação de projetos de referência, brainstorming e elaboração de um "painel conceito"v e, por último, o desenvolvimento do projeto. A bibliografia está de acordo com o tema da disciplina; no entanto, não conta com nenhum livro que apresente exemplos de estruturas de prédios altos, por exemplo, "Sistemas Estruturais" de Francis Ching (2010) ou o clássico de Heino Engel (1997). Por outro lado, nomeia um artigo da Professora Doris Kowaltowski: "Apoiando o projeto vertical: premissas básicas" que apresenta um passo a passo do processo de projeto de prédios altos, levando em consideração também os sistemas estruturais (KOWALTOWSKI et al., 2013).

Seguindo a análise do PC, constata-se que as avaliações parciais são feitas de modo continuado durante o semestre letivo, com base na participação das aulas de ateliê e nos trabalhos entregues ao final de uma das três unidades. Também são considerados os conteúdos técnicos, além de aspectos como a participação, interesse e evolução de cada discente. De modo geral, este item do documento esclarece como os alunos são avaliados, porém, não expõe quais são os principais parâmetros dessa avaliação, por exemplo, a representação dos projetos, a observância dos condicionantes legais e dos fatores técnicos (estruturas e instalações).

Identificou-se que o conteúdo programático focaliza o processo de projeto. A primeira fase da disciplina foi caracterizada por aulas sobre especificidades do projeto vertical (por exemplo, "Flexibilidade na Arquitetura" vi e outra sobre o "Custo das decisões arquitetônicas"), em seguida, por apresentações dos estudos de casos pelos alunos, aula sobre os condicionantes legais e visita de campo aos terrenos sugeridos pelos professores do mesmo período. Foi reservada uma aula para construção do painel conceito e do partido arquitetônico, e outra para elaboração dos estudos volumétricos; as demais foram divididas em itens do projeto a ser desenvolvido.

A ordem sinalizada do processo de projeto no PC de PA4 é consonante com o traçado por Kowaltowski et al. (2013), no qual estão listados aspectos que devem ser definidos em cada momento da evolução do edifício vertical. Observou-se, também, que existiu uma proposta de integração com a disciplina de Estruturas na segunda e na terceira unidades, porém, não foram estabelecidos, no conteúdo programático, momentos para esta aproximação.

\section{OBSERVAÇÃO DIRETA DA DISCIPLINA}

A observação da disciplina permitiu compreender aspectos que não foram representados no trabalho final dos alunos ou não foram comentados nas entrevistas. Foram no total 12 projetos, 
dos quais 9 foram desenvolvidos em dupla e 3 individualmente, totalizando 21 alunos na disciplina de PA4 no semestre 2018.2. Verificou-se que, em alguns momentos, a concepção estrutural teve maior influência no processo de projeto arquitetônico dos alunos, resultantes de iniciativas do docente e do delineamento de cada proposta.

Na primeira unidade, como início do processo projetual, o professor solicitou aos alunos elaborarem os "painéis conceito" através do brainstorming com o tempo máximo de 10 minutos. Os alunos também realizaram um levantamento dos condicionantes legais do bairro, analisaram as possibilidades construtivas de dois terrenos no local e escolheram um deles. A partir dessa definição, cada grupo apresentou simulações das tipologias edilícias e quais as propostas de usos para o edifício misto (empresarial ou comercial). 0 professor, então, incentivou os alunos a pensar no partido através de estudos de volumetria com isopor ou com o jogo de montar (LEGO) (Figura 1). Esta iniciativa surgiu a partir do modelo volumétrico em isopor elaborado como estudo preliminar por uma das equipes.

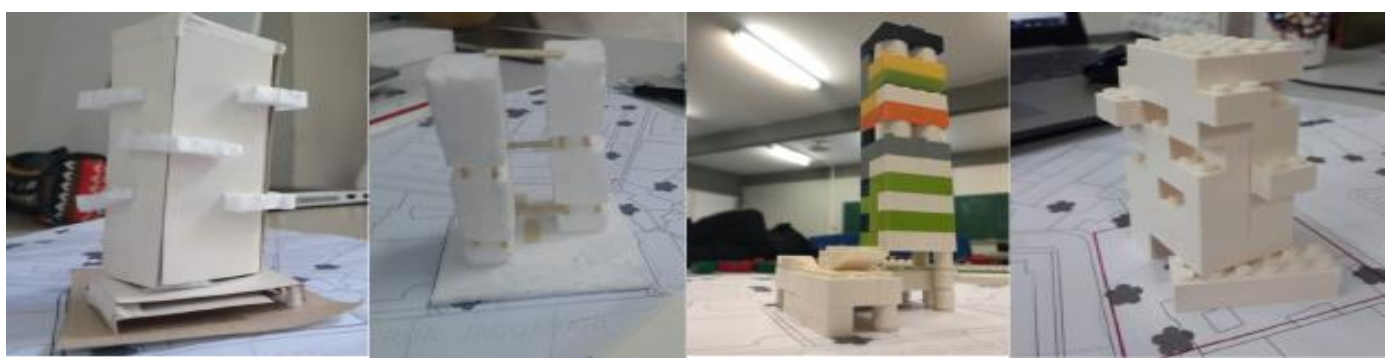

Os alunos tinham a liberdade de definir o programa de necessidades, o pré-dimensionamento, as modulações, entre outras determinantes que influenciaram no processo de projeto, gerando certa complexidade em alguns casos. Considera-se que esse poder de escolha teve consequências positivas porque os alunos sentiram uma maior autonomia no processo. Como afirmam Kowaltowski, Bianchi e Petreche (2011), o arquiteto precisa estender seu repertório em diferentes situações e problemas e, assim, aumentar suas possibilidades de achar soluções, especialmente através dos métodos de projetação que servem de apoio à aprendizagem. Por outro lado, algumas equipes geraram muitas destas restrições e tiveram certa dificuldade para resolver tais problemas, deixando, em segundo plano, aspectos mais importantes no processo de projeto de edifícios verticais como, por exemplo, entender o funcionamento dos sistemas prediais e dimensionar o vão dos elevadores de acordo com o cálculo de tráfego, ou ainda, propor uma estrutura que se libertasse da planta baixa do pavimento tipo e da circulação e estacionamento de veículos.

A segunda unidade foi o momento em que a concepção estrutural esteve mais entreposta no desenvolvimento do projeto arquitetônico dos alunos. Foi o período em que o professor incentivou mais intensamente os alunos a pensarem na forma da estrutura, seus detalhes e na sua linguagem relacionada com a Arquitetura, tendo em vista que eles já possuíam um estudo volumétrico e tinham noção de como gostariam dos espaços. Apenas uma das equipes utilizou do modelo físico durante todo o semestre e conseguiu definir uma modulação antecipadamente em relação às demais. A maior parte das duplas determinou a organização dos elementos estruturais de acordo com a planta baixa do pavimento tipo. Mais da metade dos grupos utilizou os estudos volumétricos para pensar na estrutura através do SketchUp ou Revit. É importante ressaltar o processo de projeto de uma equipe, principalmente por conta da grande influência do modo de projetar de uma das estudantes (intercambista da Argentina) através de modelos físicos (uma prática presente na sua escola de origem). Utilizaram diferentes meios de representação, alternando entre croquis à mão livre, maquete de papelão e isopor, AutoCAD e SketchUp.
Figura 1. Fotos dos estudos volumétrcos em Papelão, Isopor e LEGO

Fonte:

Trabalho dos alunos de PA4/UFRN (2018.2). 
Foi possível perceber que os alunos que tiveram mais assessorias conseguiram desenvolver o projeto de forma contínua. Neste caso, entende-se que mesmo que eles trabalhem obstinadamente, a troca de ideias e o diálogo com o professor são essenciais na aprendizagem, como afirma Donald Schön (1998).

A terceira unidade foi marcada pela revisão das questões levantadas na avaliação da segunda, o que resultou em ajustes da forma da estrutura em alguns projetos. Essas correções indicaram que não foi dada a devida atenção à concepção estrutural no início do processo de projeto, o que pode ser justificado pela ausência da equipe nas aulas destinadas às orientações, e também, pela falta de experiência em projetos em que as estruturas assumem um papel mais complexo como, por exemplo, as torres de edifícios.

A restrição do uso do concreto armado teve o intuito não só de integrar com a disciplina de Estruturas II, mas também de facilitar a representação da estrutura. E ainda, por ser um sistema construtivo mais acessível a projetos de referências e exemplos na cidade de Natal. Outra exigência de PA4 foi a utilização do BIM (Building Information Modeling) por meio do Revit na entrega do trabalho final, em acordo feito com o professor de Desenho Auxiliado por Computador 2 do semestre anterior. Essa condição foi colocada com o intuito de que os alunos ganhassem mais experiência e se acostumassem a utilizar o BIM, por se tratar de uma ferramenta atual, de qualidade integradora e com maior viabilidade de cooperação. Do ponto de vista do processo de projeto de arquitetura e da concepção estrutural, essa imposição foi favorável porque ajudou na compreensão da estrutura do edifício vertical, uma vez que o software utiliza elementos paramétricos e os alunos tiveram que modelá-los e entendê-los construtivamente, apesar de ter sido evidente a dificuldade de representação nas pranchas entregues ao final do curso, devido à falta de fluência no uso do programa. Houve, por exemplo, problemas de identificação na hierarquia das linhas do desenho técnico, especialmente nos cortes e fachadas.

Em relação à integração com a disciplina de Estruturas II, parte dos alunos consultou o professor responsável em busca de orientações para o projeto de PA4; no entanto, não houve integração efetiva das duas disciplinas. Vale comentar que, no início do semestre, o professor de estruturas propõe um trabalho em que, a partir da planta do pavimento tipo de alguns edifícios residenciais verticais, os alunos devem lançar a estrutura e fazer um prédimensionamento básico. Este talvez pudesse ser desenvolvido no momento em que os alunos estivessem projetando a fim de que eles praticassem o pré-dimensionamento da estrutura dos seus próprios projetos de edifícios verticais, haja vista o desinteresse dos alunos pelo conteúdo ofertado por essa disciplina, que é composto principalmente do dimensionamento das armações de aço de pilares, vigas e lajes em concreto.

Em resumo, pelo que foi observado no ateliê, corrobora-se que a concepção e a representação da estrutura não devem ser deixadas para um momento posterior à concepção arquitetônica; mesmo que de maneira simplificada, elas devem ser simultâneas (LARSEN, 2003; DELATORRE; TORRESCASANA, 2009). Observou-se em PA4 que o papel do professor foi fundamental como principal incentivador de um processo de projeto que leve em conta os elementos estruturais. Verificou-se, também, que o uso de modelos físicos e a utilização do SketchUp e do BIM, ou seja, a "construção" do edifício material ou virtualmente, contribuíram para a integração da concepção estrutural no processo de projeto, porque permitiram que os alunos observassem aspectos da forma e do espaço menos perceptíveis em desenhos em duas dimensões. 


\section{ENTREVISTA COLETIVA COM OS ALUNOS}

Neste item, será apresentado o ponto de vista dos discentes sobre a experiência em PA4 e algumas opiniões sobre a formação no CAU-UFRN. Dentre outras questões, destacamos: quais foram suas expectativas em relação à disciplina, suas maiores dificuldades no desenvolvimento do trabalho e o que eles conseguiram apreender do projeto de edifícios verticais. A entrevista coletiva durou cerca de 30 minutos e dos 21 alunos matriculados em PA4, 17 compareceram, dos quais mais da metade (12) participaram ativamente e opinaram sobre as questões levantadas. Vale ressaltar que as discussões em grupo são práticas frequentes entre os discentes do CAU-UFRN que promovem rodas de conversa, entre elas uma chamada Conversa Afiadavii.

Quando questionados se os projetos das disciplinas anteriores contribuíram para o desenvolvimento do trabalho, alguns alunos responderam que sim e que este "amadurecimento do conhecimento" auxilia o ato de projetar ao longo do curso. Um deles afirmou que sentiu uma grande diferença, quando comparado ao projeto do semestre anterior, no que diz respeito à restrição do uso do concreto armado porque, em comparação com a estrutura metálica, é um sistema construtivo que precisa de mais robustez para vencer grandes vãos e suportar uma quantidade significativa de pavimentos. Alguns alunos comentaram sobre conceber a planta do pavimento tipo com a estrutura do edifício e depois perceber que os pilares deveriam ser compatibilizados com os pavimentos de garagem por causa da circulação de veículos. Uma das equipes afirmou que, a partir do estudo volumétrico, a forma foi o principal fator das decisões projetuais, gerando problemas estruturais a serem resolvidos.

Quando interrogados se a estrutura influenciou no processo de projeto, a maioria respondeu positivamente. Entretanto, foi comentado que, apesar da modulação estar presente no desenvolvimento do trabalho, alguns detalhes da forma da estrutura só foram pensados posteriormente. Outra aluna afirmou: "O que acontece é que a gente tá acostumado com um modo de desenhar e deixa pra pensar na estrutura por último (...) Talvez, se desde o começo a gente tivesse integrado, não estivesse quebrando a cabeça pra solucionar o subsolo, por exemplo." (Aluna entrevistada).

Seguindo com essa questão sobre o momento da concepção estrutural, uma das estudantes comentou: "Então, primeiro e antes de tudo, eu tenho uma fachada, eu tenho uma perspectiva na minha cabeça, e não uma estrutura (...) pra mim, a gente só começa a pensar na estrutura quando começa a colocar as coisas em planta". Isto pode significar que parte considerável dos estudantes entende que a concepção estrutural deve ser um aspecto concebido no projeto de arquitetura desde o início; no entanto, eles ainda não estão habituados a colocá-lo em prática. De acordo com um dos participantes da entrevista, a orientação dada em algumas disciplinas, do ponto de vista da concepção estrutural, está "ao contrário", porque elas são feitas a partir de uma planta baixa já definida, na qual serão colocados os elementos estruturais. Outro comentário foi que o primeiro passo deveria ser definir qual o sistema construtivo e identificar o maior vão que o material suporta, porém, essas informações ainda são insuficientes diante de todas as tomadas de decisão referentes às estruturas.

Sobre o "exercício da concepção estrutural" de Estruturas II, foi comentado que ele trouxe uma visão de como a estrutura se comporta em edifícios verticais e ajudou na elaboração do projeto de PA4. Contudo, a abordagem da disciplina e o conteúdo apresentado ao longo do semestre parecem distantes da realidade dos arquitetos. A maioria dos estudantes acredita que existe a possibilidade de uma maior aproximação desses componentes curriculares, sobretudo se a primeira dedicasse um maior tempo à concepção estrutural aplicada ao projeto do ateliê. 
Em relação às restrições de projeto, o único aspecto comentado foi a imposição da utilização do concreto armado. Os alunos comentaram que é o sistema construtivo mais utilizado na região, mas alguns deles gostariam de aprender outras possibilidades de construção de edifícios verticais.

Em síntese, a maior parte dos discentes que participaram da dinâmica de grupo considera ainda não estar preparada para conceber estruturas mais complexas. Seus projetos, muitas vezes, são adequados às formas estruturais e, consequentemente, perdem características pensadas inicialmente no estudo volumétrico. Reconhecem que a concepção estrutural deve acontecer em conjunto com a criação do espaço, e por isso, precisam aprender a colocá-la em prática.

\section{O PONTO DE VISTA DO PROFESSOR}

A entrevista aconteceu reservadamente e durou aproximadamente 25 minutos. Segundo o professor, foram necessárias estratégias para estimular os alunos a pensar na estrutura e foram identificadas dificuldades previstas no processo de projeto, o que justificou a imposição do sistema construtivo em concreto.

Quanto ao grau de influência das disciplinas de Estruturas no desenvolvimento do projeto do edifício vertical de PA4, o professor considerou que as disciplinas estão bem posicionadas na organização curricular do CAU/UFRN. Entretanto, existe uma certa distância entre o conteúdo referente aos sistemas estruturais e o processo projetual. Acredita que isso se dá por conta da falta de iniciativa, por parte dos alunos, em buscar mais informações sobre este tema e que, em vários casos, os alunos se fazem de "vítimas" em relação às disciplinas de Estruturas. Comentou que a restrição para o uso do concreto armado teve também a finalidade de integrar com a disciplina de Estruturas II e porque a maior parte dos edifícios verticais construídos na região usa este sistema estrutural.

Quando questionado se a concepção estrutural foi um dos aspectos priorizados no desenvolvimento dos projetos dos alunos, a resposta foi negativa, mas explicou que tentou estimular os alunos a pensarem na racionalização durante a locação dos pilares, e que, ao desenvolver a solução em planta, atentassem para como isso iria afetar os pavimentos inferiores. Ele entende que muitos alunos tiveram dificuldades de resolver os subsolos; no entanto, todos foram alertados desde o início sobre estas particularidades do edifício vertical.

Por fim, verificou-se que o docente se preocupa com a inserção da concepção estrutural no ateliê de projeto, compreende que existem peculiaridades da integração da estrutura com a arquitetura em prédios verticais e procura estimular os alunos a pensar nestas questões. A imposição do uso do concreto armado teve o propósito de facilitar o aprendizado dos sistemas estruturais de edifícios altos, que são mais complexos do que os projetos realizados nos semestres anteriores do CAU/UFRN.

\section{ANÁLISE DOS PROJETOS DISCENTES}

Nesta análise, foram quatro itens verificados: a facilidade de identificação da estrutura; se houveram projetos de referência; se há alguma lógica estrutural e o grau de desenvolvimento da estrutura no projeto. Uma das equipes não cumpriu boa parte das exigências feitas e outra não concluiu o trabalho; desta maneira, optou-se pela análise dos dez projetos entregues e adequados ao que foi formulado como exercício.

Evidenciou-se, na análise dos desenhos técnicos, que a maior parte dos alunos teve dificuldade no momento da compatibilização da estrutura do tipo com os pavimentos de garagem 
(subsolos). Em sete dos projetos estavam desenhados os pilares do pavimento tipo, mas eles não estavam evidentes nas plantas baixas dos pavimentos de garagem. Nenhuma dupla apresentou projetos de referência no trabalho final da disciplina; no entanto, durante o semestre o professor levou revistas que auxiliaram algumas equipes em relação à forma e à estética do sistema estrutural.

Já em relação à lógica estrutural, todos os projetos seguiram o mesmo modelo do pórtico tridimensional (Figura 2). Talvez isso se dê porque, em um primeiro momento, é o tipo que parece mais intuitivo em se tratando do concreto armado como material construtivo. Todavia, há uma variação entre eles quanto à importância acordada à lógica estrutural, ou seja, algumas equipes estavam mais atentas para a forma segundo os caminhos das forças estruturais do que outras. Quanto ao grau de desenvolvimento da estrutura, nenhuma equipe a desenvolveu em sua totalidade, pois em todos os projetos existiram algum tipo de desenho em que a estrutura não foi representada. Pretendeu-se identificar se os alunos pensaram na estrutura apenas seguindo um modelo simples do encaminhamento das forças e desenvolveram um pouco mais do projeto em relação à estrutura a partir disto, ou se tentaram ir além da lógica estrutural e, consequentemente, não conseguiram reproduzi-la nos seus trabalhos. Para tanto, considerouse a escala: 0-Nenhum, 1-Baixo, 2-Médio, 3-Alto e 4-Avançado. 0 gráfico abaixo apresenta no eixo $\mathrm{X}$ o grau de desenvolvimento da estrutura e o $\mathrm{Y}$ a lógica estrutural, os pontos representam os projetos dos alunos.

No tocante à lógica estrutural, foram 6 projetos considerados como de nível médio (2) e 4 como alto (3), o que mostra que nenhum deles a desconsiderou completamente, mas, também, nenhum deles baseou-se essencialmente nesse aspecto para projetar o edifício. Sobre o grau de desenvolvimento da estrutura, 2 dos trabalhos foram avaliados como nível baixo (1), metade (5) como nível médio (2), e 3 como de nível alto (3). Comparando as duas características, viu-se que dos 4 projetos que foram avaliados como alto (3) pela lógica estrutural, sendo que apenas 1 conseguiu desenvolver e representar melhor a estrutura (alto3). Enfim, 3 dos 10 projetos analisados foram considerados como de médio (2) desempenho nos dois aspectos (meio do gráfico).
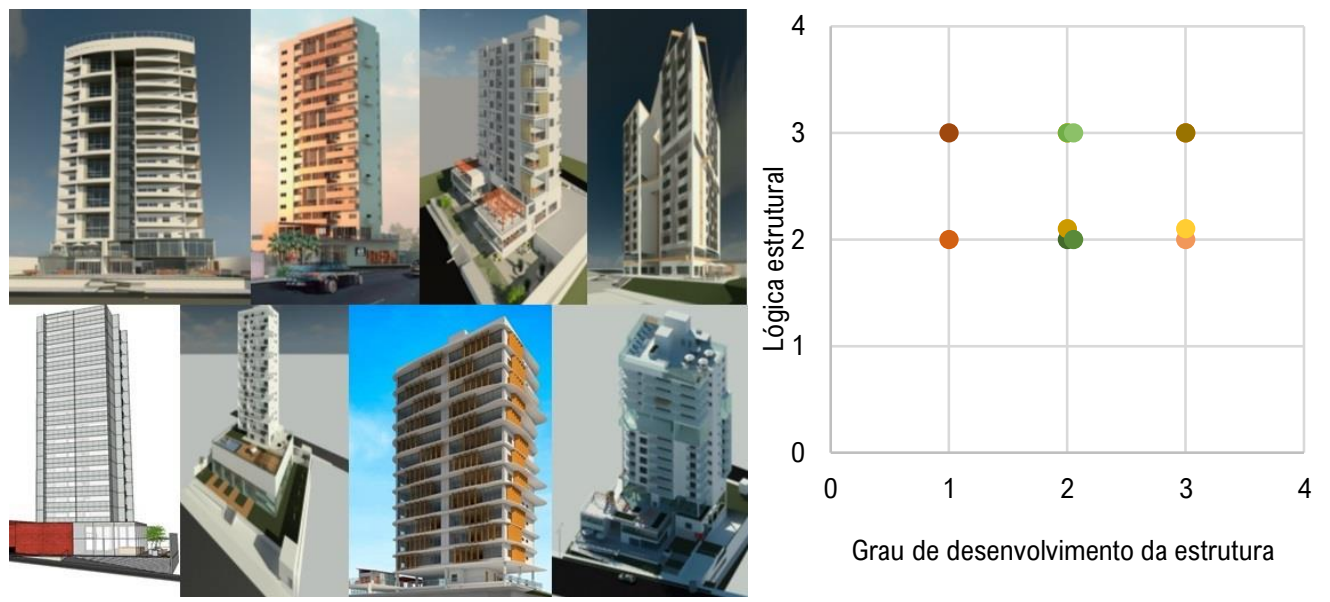

Em resumo, na análise dos projetos dos alunos, observou-se que poucas equipes conseguiram pensar na lógica estrutural de maneira considerada mais avançada e, ao mesmo tempo, conceber a estrutura de forma mais completa. Pode-se afirmar que a maior parte deles foi considerada com desempenho mediano nestes dois aspectos.
Figura 2. Perspectivas dos projetos dos discentes pórticos tridimensionais $(a$ esquerda).

Fonte:

Trabalho dos alunos de PA4/UFRN (2018.2).

Gráfico 1. Grau de desenvolvimento da estrutura $x$ lógica estrutural - Projetos dos alunos (a direita)

Fonte:

Autoria própria. 


\section{ANÁLISE GLOBAL DA DISCIPLINA DE PROJETO DE ARQUITETURA 4}

Algumas considerações podem ser destacadas sobre a inserção dos sistemas estruturais no processo de projeto dos discentes e nos resultados finais da disciplina de PA4. Conforme o Plano de curso da disciplina, a organização dos conteúdos e o planejamento dos momentos de concepção se mostraram positivos, promoveram um bom desenvolvimento do trabalho e apontaram caminhos a serem seguidos, com base no artigo sobre o projeto vertical usado como importante referência (KOWALTOWSKI et al., 2013). Já na observação em sala de aula, verificou-se a importância do incentivo ao desenvolvimento do estudo volumétrico, do estímulo à concepção da estrutural e do uso modelos físicos, mesmo que esses tenham servido apenas para a visualização tridimensional do edifício, ou seja, sem o propósito de compreensão do sistema estrutural ou de análise dos elementos estruturais, conforme observado anteriormente (VRONTISSI et al., 2018). Cabe também ressaltar os programas de modelagem geométrica e paramétrica, os quais contribuíram consideravelmente nessa integração do projeto e sua estrutura.

Pelo discurso dos alunos, foi possível perceber que eles reconhecem a relevância do aprendizado em estruturas, mas acham que ele poderia ser mais bem aplicado à concepção arquitetônica. E, também, que gostariam de ter mais autonomia na escolha dos materiais e sistemas construtivos, porque acreditam que isso possibilitaria uma maior liberdade formal no processo de projeto. Por outro lado, o professor afirma que esta decisão foi favorável, já que muitos dos alunos tiveram sérias dificuldades no desenvolvimento da estrutura, apesar de ser um material construtivo tão difundido na região. Foi possível perceber, também, que ele reconhece o valor da integração da concepção estrutural dentro do processo de projeto de arquitetura e como isso afeta o aprendizado dentro do ateliê.

Em se tratando dos projetos produzidos pelos alunos, como visto no gráfico comparativo da avaliação da lógica estrutural com o grau de desenvolvimento da estrutura nos projetos, quase todos os trabalhos foram avaliados como medianos. Nenhum deles apresentou uma proposta estrutural diferente, por exemplo, com um eixo estruturante no meio ou, talvez, a estrutura mais situada na periferia do edifício, de maneira a mostrar sua expressividade na fachada. Sabe-se que é necessária certa experiência no ato de projetar para liberar mais facilmente a criatividade e elaborar projetos mais inusitados; todavia, não seriam os ateliês de projeto dos cursos de arquitetura e urbanismo uma oportunidade ímpar de testar e descobrir novas ideias, sem o peso das imposições do mercado imobiliário (como restrições de custo, programáticas, dentre outras)?

\section{CONSIDERAÇÕES FINAIS}

Entende-se que as estruturas são restrições práticas (LAWSON, 2011) inseridas no ensino/aprendizado no projeto de arquitetura, que envolve, segundo Schön (1998), um processo prático-reflexivo no qual os alunos devem refletir-na-ação. Ensinar e aprender a concepção estrutural no ateliê de projeto de arquitetura é um desafio para os docentes e alunos que exige conhecimento técnico e criatividade (HERR, 2013; WHITEHEAD, 2013). São muitos pontos considerados durante o processo de projeto e que concorrem com a estrutura na produção do espaço arquitetônico (CHIUINI, 2006). Em se tratando de edifícios altos, as questões estruturais são intensificadas e devem ser estimuladas durante a produção dos projetos dos alunos. Ensinar a concepção arquitetônica e estrutural juntas vai exigir do professor um esforço maior no ateliê e muitas vezes um trabalho colaborativo com docentes da área de Tecnologia (estruturas e instalações prediais, principalmente). 
Uma constatação importante feita nessa pesquisa é que os alunos tratam em geral as disciplinas de Estruturas e, consequentemente, os elementos estruturais, como "vilões" do processo de projeto e acreditam que seus assuntos não serão aplicáveis ao ato de projetar (REBELLO; LEITE, 2015), o que foi confirmado pelo docente em seu discurso e como também afirma Chiuini (2006). Talvez isso se deva ao fato dos conteúdos ministrados nas disciplinas de Estruturas estarem um pouco distantes da realidade do ato de projetar em arquitetura (conforme discurso dos discentes), com o qual os alunos de arquitetura estão mais acostumados (WHITEHEAD, 2015).

Ao contrário da concepção arquitetônica, considerada aberta, livre e criativa, a concepção estrutural é vista como uma matéria da engenharia, pautada na objetividade e na técnica, que necessita de uma "resposta correta". No entanto, a concepção estrutural pode constituir uma resposta satisfatória a um problema de projeto pois está integrada à matéria da Arquitetura, que é por natureza divergente na maneira de pensar, o que significa que, para um problema dado, não há uma única solução. Entende-se que o ensino do Projeto de Arquitetura é complexo e envolve professores e alunos em situações de diálogo e crítica. A integração da concepção estrutural adiciona mais uma dificuldade nesse processo, mas estimula uma prática muito mais reflexiva em relação às formas usuais do ensino de Estruturas.

\section{Agradecimentos}

Agradecemos ao professor e a todos os discentes da disciplina PA4/CAU/UFRN por aceitarem participar dessa pesquisa e, também, à Coordenação de Aperfeiçoamento de Pessoal de Nível Superior (CAPES) pelo apoio financeiro à pesquisa por meio da concessão de uma bolsa de doutorado.

\section{Referências Bibliográficas}

BOUDON, Philippe; DESHAYES, Philippe; POUSIN, Frédéric; SCHATZ, Françoise. Enseigner la conception architecturale. Paris: Édition de la Villete, 2000.

CHIUINI, Michele. Less Is More: A Design-oriented Approach to Teaching Structures in Architecture. In: BUILDING TECHNOLOGY EDUCATORS' SYMPOSIUM, 2006, Maryland. Anais [...]. Maryland, 2006, p. 205-218.

DELATORRE, Vivian; TORRESCASANA, Carlos Eduardo N. Integração entre arquitetura e estrutura: um estudo para as disciplinas de projeto arquitetônico. In: SEMINÁRIO INTEGRADO: ENSINO, PESQUISA E EXTENSÃO, 3., 2011, Chapecó. Anais [...]. Chapecó: UNOCHAPECÓ, 2011.

EMAMI, Niloufar; BUELOW, Peter Von. Teaching structures to architecture students through handson activities. In: CANADIAN INTERNATIONAL CONFERENCE ON ADVANCES IN EDUCATION, TEACHING, AND TECHNOLOGY, 1., 2016, Toronto. Anais [...]. Toronto: Ryerson University, 2016.

FLORIO, Wilson; TAGLIARI, Ana. Modelos físicos na prática de projeto de edifícios: uma experiência didática. Revista Projetar: Projeto e Percepção do Ambiente, v. 2, n. 2, p. 13-26, 2017.

HERR, Christiane M. Qualitative structural design education in large cohorts of undergraduate architecture students. Global Journal of Engineering Education, v. 15, n. 2, p. 96-102, 2013.

ILKOVIČ, Ján; ILKOVIČOVÁ, Lubica; ŠPACEK, Robert. To think in architecture, to feel in structure: Teaching Structural Design in the Faculty of Architecture. Global Journal of Engineering Education, $v$. 16, n. 2, p. 59-65, 2014. 
O ensino da concepção estrutural no ateliê de projeto de edifícios verticais: um estudo de caso na Universidade Federal do Rio Grande do Norte

KOWALTOWSKI, Doris C. C. K.; BIANCHI, Giovana; PETRECHE, João R. D. A criatividade no processo de projeto. In: $\mathrm{O}$ processo de projeto em arquitetura: da teoria à tecnologia. São Paulo: Oficina de Textos, 2011. p. 26-56.

KOWALTOWSKI, Doris C. C. K.; BORGES, Francisco; SURAIA, Filho; FARAH, Felipe. Apoiando o Projeto Vertical: Premissas Básicas. In: ENCONTRO NACIONAL DE CONFORTO NO AMBIENTE CONSTRÍUDO, 12/ ENCONTRO LATINO AMERICANO DE CONFORTO NO AMBIENTE CONSTRUÍDO, 8.,2013, Brasília. Anais [...].Brasília: UNB, 2013, p. 1-10.

LARSEN, Olga Popovic. Conceptual Structural Design: Bridging the gap between architects and engineers. 2. ed. Londres: ICE Publishing, 2003.

LAWSON, Bryan. Como arquitetos e designers pensam. São Paulo: Oficina de Textos, 2011.

LEBAHAR, Jean-Charles. Approche didactique de l'enseignement du projet en architecture: étude comparative de deux cas. Didaskalia, n. 19, p. 39-77, 2001. DOI: 10.4267/2042/23908.

LOBOSCO, Tales; CÂMARA, Débora Carvalho. Desenvolvimento de modelos qualitativos para o ensino de estruturas. PARC Pesquisa em Arquitetura e Construção, v. 9, n. 3, p. 203-214, 2018. DOI: 10.20396/parc.v9i3.8650263.

MAC NAMARA, Sinead C.. Bringing Engineering into the Studio: Design Assignments for Teaching Structures to Architects. American Society of Engineering Education, p. 1-12, 2012. DOI: 10.18260/1$2-21028$.

NÓBREGA, Petrus Gorgônio Bulhões; COSTA, Fernando José de Medeiros. Avaliação crítica do ensino de estruturas: enigma da esfinge? In: ENCONTRO NACIONAL DE ENSINO DE ESTRUTURAS EM ESCOLAS DE ARQUITETURA, 3., 2017, Ouro Preto. Anais [...]. Ouro Preto: UFOP, 2017. p. 126-140.

PIÑÓN, Hélio. Curso Básico de Proyectos. Barcelona: UPC, 1998.

PINTO, Jorge Cruz. Processos e Metodologias de Projeto. Lisboa: Coleção Didática, 2007.

REBELLO, Yopanan Conrado Pereira; LEITE, Maria Amélia Devitte Ferreira D’Azevedo. Considerações sobre o ensino e aprendizagem de estrutura nas escolas de Arquitetura. Paranoá: cadernos de arquitetura e urbanismo, n. 15, p. 1-14, 2015. DOI: 10.18830/issn.1679-0944.n15.2015.01.

SARAMAGO, Rita de Cássia Pereira. Ensino de estruturas nas escolas de arquitetura do Brasil. Dissertação (Mestrado em Arquitetura, Urbanismo e Tecnologia) - Escola de Engenharia de São Carlos, Universidade de São Paulo, São Carlos, 2011.

SCHÖN, Donald A. Educando o profissional reflexivo: um novo design para o ensino e a aprendizagem. Porto Alegre: Artmed, 2000.

SIMONEN, Kathrina. Iterating structures: Teaching engineering as design. Journal of Architectural Engineering, v. 20, n. 3, p. 1-10, 2014. DOI: 10.1061/(ASCE)AE.1943-5568.0000152.

VRONTISSI, Maria; CASTELLÓN GONZÁLEZ, Juan J.; D’ACUNTO, Pierluigi; MONZÓ, Lluís E.; SCHWARTZ, Joseph. "Constructing Equilibrium": A methodological approach to teach structural design in architecture. In: INTERNATIONAL CONFERENCE ON STRUCTURAL ENGINEERING EDUCATION WITHOUT BORDERS, 4., 2018, Madrid. Anais [...].Madrid: Instituto de Ciencias de la Construcción Eduardo Torroja, 2018. p. 617-627.

WETZEL, Catherine. Integrating structures and Design in the first-year studio. Journal of Architectural Education, v. 66, n. 1, p. 107-114, 2012. DOI: 10.1080/10464883.2012.715980. 
WHITEHEAD, Rob. Supporting Students Structurally : Engaging Architectural Students in Structurally Oriented Haptic Learning Exercises. In: ARCHITECTURAL ENGINEERING CONFERENCE, Condado de Centre, 2013. Anais [...] Condado de Centre: State College, 2013. DOI: 10.1061/9780784412909.023.

WHITEHEAD, Rob. Comprehensive and Creative Conclusions: Enhancing Structural Design Educational Opportunities in Labs for Architecture Students. In: ARCHITECTURAL ENGINEERING CONFERENCE, 2015, Milwaukee. Anais [...]. Milwaukee: Milwaukee School of Engineering, 2015. p. 469-482. DOI: 10.1061/9780784479070.041.

WHITEHEAD, Robb. Structures by design. Nova lorque: Routledge, 2020.
Camila Resende camilacresende@gmail.com

Maísa Veloso maisaveloso@gmail.com

\section{Notas}

i Muitos autores (LARSEN, 2003; SARAMAGO, 2011; WHITEHEAD, 2020) comentam sobre o "sentimento estrutural" ou "intuição" como a forma de projetar a estrutura baseado nas experiências pessoais do projetista e no entendimento e previsão do comportamento físico dos sistemas estruturais.

ii O "instrucionismo", neste caso, trata-se da abordagem didática com aulas tipo palestras na qual o aluno é passivo no aprendizado (NÓBREGA; COSTA, 2017).

iii O "construcionismo", por sua vez, pauta-se na teoria do aprender fazendo, tendo como referência ao ato de construir, a exemplo dos Canteiros Experimentais (NÓBREGA; COSTA, 2017). iv Caracterizado por múltiplos andares (normalmente mais que 10) ou pela sua altura total (maior que $30 \mathrm{~m}$ ), mas também pela proporção entre altura e largura (prédios com proporção igual ou maior que 10:1 precisam de medidas estruturais especiais) (WHITEHEAD, 2020).

$\checkmark$ Painel de apresentação do conceito do projeto, através da identificação de uma palavra (ou mais de uma) que resuma $(\mathrm{m})$ as qualidades que se pretende imprimir ao edifício e, que, por sua vez, determinarão as principais decisões projetuais.

vi Conceito que trata da perenidade do edifício e da elaboração de um programa que possa suportar adaptações de novos usos, as possibilidades de ampliações e a questão de impedimento de novos usos para espaços muito especializados.

vii "Conversa Afiada" é o nome das rodas de conversas organizadas pelo Centro Acadêmico (CA) do CAU/UFRN, e que tem como principal objetivo tratar assuntos relevantes que surgem durante a graduação. A partir de uma demanda ou tema importante que os estudantes gostariam e considerem necessário abordar, o CA convida um palestrante que dá início ao debate que comumente acontece no átrio do Bloco dos Laboratórios de Arquitetura localizado no campus central da UFRN. 